\title{
Changes in the Brazilian Annals of Dermatology. Unpostponable initiatives
}

DOI: http:/ /dx.doi.org/10.1590/abd1806-4841.2019940201

Dear Colleagues,

Our journal, Brazilian Annals of Dermatology, was indexed in PubMed in 2009, and in 2010 had its Impact Factor (IF) assessed and disclosed in the Journal Citation Report (JCR). As you know, in spite of its limitations, the IF of a certain journal is its "business card", and its proof of quality and reputation, and also the parameter for Capes in determining the Qualis index of journals in general. The IF is calculated by dividing the number of citations the journal receives in a certain year for the articles published (for example: in 2017), by the number of articles published in the two previous years (in the example: 2016 and 2015). In 2017, it corresponded to 357 citations to 404 published articles. Therefore, the IF of 2017 was of 0.884 . What qualifies us by Capes as a B3 journal (from A1 to B5). And, of 63 dermatology journals that were assessed/measured by the JCR, we are in the $60^{\text {th }}$ place. We cannot accept such classification. It does not do justice to Brazilian dermatology.

We have been taking multiple initiatives to reverse this picture, such as: reducing the overall number of articles, particularly case reports, pursuing review articles and more attractive and upto-date CME, favoring publications in the scope of tropical dermatology, and being very strict regarding the articles submitted. However, we understand this alone is not enough. We need to increase our visibility, particularly towards our international peers; with this goal we need to speed up our publications with the long-awaited ahead of print, expedite the review of submitted manuscripts, better qualify and standardize texts in English and refresh some design aspects of the journal.

For this, we will associate with Elsevier publishing company, which will take responsibility for the graphic production, distribution, inclusion of article links on its website, relationship with PubMed, Portuguese translation and English version, final review with authors and, lastly, publication keeping an open access format, starting in May/June.

This bold but necessary step does not mean we will abandon the Portuguese journal in print. But it does mean that the submission system will be in English, different from the current one, that the deadlines for authors, partners and editors will be slimmer and more disciplined, that the front page layout will change, among other international publication standards that the publisher will certainly contribute with.

Ultimately a step forward, that will have to be followed by the dermatology community in terms of challenges regarding the quality of the articles, photographs, reports and support and respect to the journal that represents us. Always remembering to praise us with citations, when indicated, when publishing in other journals, therefore contributing to increasing the IF of our journal and validating Ibero-Latin American dermatology.

Warm regards,

\section{Sinésio Talhari}

Universidade Federal do Amazonas (UFAM), Fundação Alfredo da Matta (FUAM) e Universidade Nilton Lins - Manaus (AM), Brazil

Bernardo Gontijo

Universidade Federal de Minas Gerais (UFMG) - Belo Horizonte (MG), Brazil

Everton Carlos Siviero do Vale

Universidade Federal de Minas Gerais (UFMG) - Belo Horizonte (MG), Brazil

Silvio Alencar Marques

Universidade Estadual Paulista (UNESP) - Botucatu (SP), Brazil

\begin{tabular}{lrr}
\hline Sinésio Talhari & (iD) ORCID & $0000-0001-9753-6706$ \\
Bernardo Gontijo & (iD) ORCID & $0000-0003-1938-5986$ \\
Everton Carlos Siviero do Vale & (iD) ORCID & $0000-0002-9172-3639$ \\
Silvio Alencar Marques & iD ORCID & $0000-0002-5512-4700$
\end{tabular}

